\title{
Cytogenetic Effect of Heavy Metal Exposure in Alzheimer's Disease Rat Model
}

\author{
Marwa A. Essa ${ }^{1^{*}}$, Iman H. Ibrahim ${ }^{2}$, Ezzat I. Aboul-Ela ${ }^{3}$ \\ ${ }^{1}$ Department of Biochemistry, Faculty of Pharmacy, October 6 University, Giza, Egypt. \\ ${ }^{2}$ Department of Biochemistry and Molecular Biology, Faculty of Pharmacy (Girls), Al-Azhar University, Cairo, \\ Egypt. \\ ${ }^{3}$ Department of Genetics and Cytology, Division of Genetic Engineering and Biotechnology, National Research \\ Centre, Dokki, Giza, Egypt \\ *Correspondence: e-mail: marwaashraf@,06U.edu.eg
}

\section{Article history: Received: 2021-06-11 Revised: 2021-06-29 Accepted: 2021-07-10}

\begin{abstract}
The widespread heavy metal, potassium dichromate (PDC), presents an actual threat because of its high toxicity to all body organs. This research was designed to study the possible cytotoxicity and genotoxicity exerted by PDC on Alzheimer's disease (AD) and the prospect negative effect on AD induced in rats. The current research was performed on forty male rats, classified similarly into 4 sets: normal control, AD control was done by intraperitoneal injection of lipopolysaccharide (LPS) at a dose $250 \mu \mathrm{g} / \mathrm{kg}$ body weight for 7 days, $\mathrm{AD}$ rats intraperitoneally injected once by PDC $10 \mathrm{mg} / \mathrm{kg}$ body weight, and PDC-intoxicated rats (same dose as the third group). The fourth group served to compare the effect of PDC alone. Twenty-four hours after the PDC injection, rats were sacrificed to collect their brain hippocampi (CA3 region) to study its histopathological structure, acetylcholinesterase (AChE) gene expression by RT-PCR, malondialdehyde (MDA) content and catalase (CAT) activity spectrophotometrically. Additionally, cells of the bone marrow were harvested from the rat femoral bone to undergo in-vivo micronucleus (MN) assay. The outcomes entailed that AD rats with PDC significantly altered the hippocampal histology, vanished neuronal survival count, increased AChE gene expression, MDA content and CAT activity in AD rats more than normal and PDC-only rats. Furthermore, PDC significantly elevated frequency of $\mathrm{MN}$ in $\mathrm{AD}$ rats' bone marrow cells. In conclusion, the study results evidenced that PDC exerted a tremendous harm to the AD case, evident by all previously mentioned outcomes.
\end{abstract}

Keywords: Potassium Dichromate, Alzheimer's Disease, Lipopolysaccharide, Micronucleus, Cytotoxicity, Genotoxicity.

\section{INTRODUCTION}

Genotoxic heavy metals are compounds that encounter an ability to enter the brain and accumulate, which in several cases done by ruining the blood brain barrier. These pernicious compounds accumulate and trigger pathways that alter neurochemistry which supports intellectual function 1. Chromium (Cr) is a heavy metal found naturally and represents the seventh most available element on earth. There are two oxidation conditions that chromium occurs in the natural environment, $\mathrm{Cr}^{3+}[\mathrm{Cr}(\mathrm{III})]$ and $\mathrm{Cr}^{6+}[\mathrm{Cr}(\mathrm{VI})]^{2}$. Out of the two chromium forms, $\mathrm{Cr}^{6+}$ is the most labile, mobile and toxic form. Potassium dichromate (PDC) $\left(\mathrm{K}_{2} \mathrm{Cr}_{2} \mathrm{O}_{7}\right)$ is a great source of $\mathrm{Cr}^{6+}$, where it is used in the chrome industry to manufacture pigments and dyes, in addition to antiseptics preparation ${ }^{3}$. The widespread use of $\mathrm{Cr}^{6+}$ to produce stainless steel leads to occupational exposure of millions of workers all over the world to the hazardous vapour during its production ${ }^{4}$. PDC is a potent oxidizer, so it is harmful to biological systems. Due to its solubility, it is highly transportable in the milieu and offers an excessive source of toxicity, mutagenicity, teratogenicity, and carcinogenicity. It can create reactive oxygen species throughout its reduction process, and these suspicious compounds can result 
in damage to the DNA, lipids and proteins of the cell 5 .

One of the major neurodegenerative disorders worldwide is Alzheimer's disease (AD), that is characterized by continuing decrease of cognitive jobs and memory. Based on recent statistics, about 6.2 million Americans aged 65 and older are living with Alzheimer's dementia in 2021 ${ }^{6}$. Its pathological changes are observed mainly in the hippocampal and cortical regions ${ }^{7}$. AD is developed due to decrease in acetylcholine (ACh) in the brain by extensive breakdown via acetylcholinesterase (AChE), deposition of amyloid- $\beta$ (A $\beta)$ extracellularly and hyper-phosphorylated tau intraaxonly, forming neurofibrillary tangles ${ }^{8}$. ACh plays important roles in learning and memory 9 . The cholinergic system is rigorously affected in $\mathrm{AD}$, implicating its role in memory. A common feature in $\mathrm{AD}$ brain is the presence of AChE in high levels, which is commonly associated with $\beta$-amyloid plaques and neurofibrillary tangles ${ }^{10}$.

Neuro-inflammation is known to have a role in the pathological processes of $\mathrm{AD}^{11}$. Activation of microglia may contribute to the neurodegenerative process through the discharge of proinflammatory cytokines, and other toxic yields ${ }^{12}$. Lipopolysaccharide (LPS) is a powerful endotoxin, derived from Gram-negative bacterial cell wall, that can start different pathological impacts in humans and animals. Latest studies suggest that chronic exposure to LPS can result in neurodegeneration and consequent $\mathrm{AD}^{13}$.

Several studies have shown that imbalance in metal homeostasis may lead to neuronal loss in neurodegenerative diseases ${ }^{14}$. Maynard suggested that dietary metals could influence $A \beta$ deposition in the brain under certain conditions, through decreasing $A \beta$ clearance ${ }^{15}$. Moreover, it was observed that acetylcholine level was decreased in cortex, hippocampus and amygdala of rats intoxicated with heavy metals, clarifying that cholinergic insufficiencies can cause cognitive impairment ${ }^{16}$.

The micronucleus (MN) test is the utmost commonly undertaken in vivo mammalian genotoxicity assessment. It was known in the $19^{\text {th }}$ century end ${ }^{17}$. This assay was established as a technique to estimate the frequency of micronucleated erythrocytes amongst normal erythrocytes, which have no nuclei throughout hematopoiesis. The sample used in this assay is either bone marrow or peripheral blood cells of animals 18,19. Formerly, it was stated that MN occurs when acentric fragments, or the whole chromosomes, cannot integrate into the daughter nuclei during mitosis. It has been revealed that mitotic apparatus (spindle, kinetochores) disorders and diminished role of topoisomerase II is captivated in micronucleus formation. Accordingly, counting $\mathrm{MN}$ in cytoplasm of the interphase daughter cell has been utilized to evaluate aneugenic or clastogenic chromosomal DNA damage ${ }^{20}$.

Based upon the above-mentioned data, our study aimed to elucidate the PDC potential on AD in rats, by investigating the cytotoxicity and genotoxicity of PDC following an intraperitoneal injection. In addition, studying changes in the expression of AChE, oxidative stress biomarkers levels, as well as histopathological impact on the hippocampus responsible for memory.

\section{METHODS}

\subsection{Reagents and Chemicals:}

Lipopolysaccharide from Escherichia coli; O127:B8 was obtained from Sigma Aldrich, Saint Louis, MO, USA. Potassium dichromate was purchased as an orange powder from Alpha Chemika, India. RNA extraction QIAamp RNeasy Mini kit, purification of Total RNA kit and SYBR Green Master Mix for PCR were bought from Qiagen, Germany. Primers used were supplied from Metabion, Germany. Hematoxylin, eosin and toluidine stains were supplied from Merck, Germany. The other used chemicals were analytically highly pure.

\subsection{Animals:}

Forty male Wistar rats, aged 8-12 weeks old, and weighed about 180-220 g were obtained from the animal house colony of The Egyptian Organization for Biological Products and Vaccines (Cairo, Egypt), to be utilized in the current study. The rats were tail-marked to be distinguished, individually weighed and randomly allocated to one of the four groups to avoid significant differences within body weights and age of each group. Rats were accommodated in common polypropylene cages in the animal house located in Faculty of Pharmacy, October 6 University, three to four rats per cage, at room temperature $\left(25 \pm 2{ }^{\circ} \mathrm{C}\right)$, under controlled light (10h light: $14 \mathrm{~h}$ dark). Animals were permitted to adapt to their milieu for one week preceding the experimental procedures. Normal pellet diet and $\mathrm{H}_{2} \mathrm{O}$ ad libitum were delivered to the rats along the experiment period.

\subsection{Experimental design:}

The rats were allocated into 4 groups (10 rats in each group). The first group was named as normal control, received normal saline i.p. for 7 days. The second group was considered as the AD control, received LPS $250 \mu \mathrm{g} / \mathrm{kg}$ body weight dissolved in cold $0.9 \% \mathrm{NaCl}$, i.p. for 7 successive days ${ }^{21}$, to 
induce systemic inflammatory response and consequent neuroinflammation similar to $\mathrm{AD}$. The third group was allocated for $\mathrm{AD}$ rats receiving the heavy metal, PDC, where AD was induced just as the second group, followed by PDC $(10 \mathrm{mg} / \mathrm{kg}$ body weight single i.p. injection freshly dissolved in saline ${ }^{22}$ ) one hour after the last LPS injection. While the forth group was assigned to investigate the effect of PDC alone, as they were PDC-injected just as the third group, but one hour after the last i.p. saline injection that lasted for 7 successive days. The overall design is shortly summarized in Figure 1.

All rats were then ether- euthanized, and sacrificed by decapitation after 24 hours of their last injection. Brains of 6 rats/ group were harvested instantly after decapitation and rinsed with cold normal saline, hippocampi were dissected out and quickly saved at $-80^{\circ} \mathrm{C}$ for determination of $\mathrm{AChE}$ gene expression, MDA content and CAT activity. We used $10 \%$ formaldehyde (buffered) to fix the brains of 4 rats from each group for subsequent histopathological examination. Moreover, both of the femurs were removed from 4 rats/ group, and were allocated for micronucleus assay.

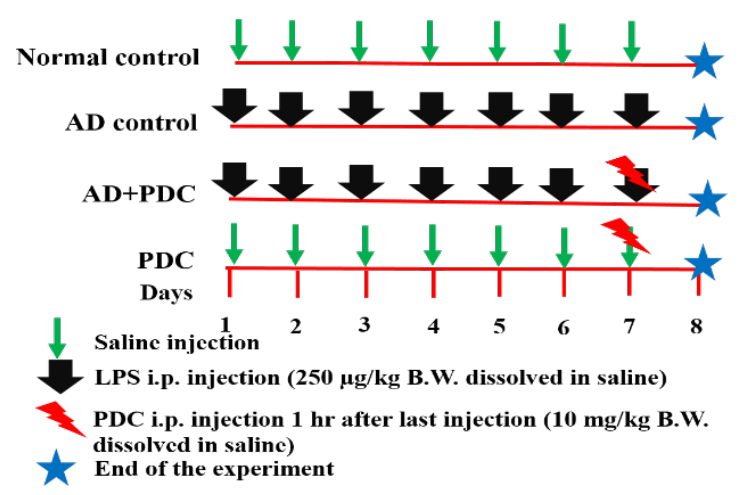

Figure 1: Diagram presenting the experimental design

\subsection{Brain hippocampal assessment of AChE genetic expression:}

This was undergone using quantitative real time polymerase chain reaction (qRT-PCR) technique. Concisely, isolation of RNA was done via RNeasy RNA abstraction kit, according to the producer's directions (Qiagen). DNase I was added to RNA and reverse transcription following manufacturer's protocol, was done. Quantitative real-time PCR was performed with SYBR Green master mix in a Stratagene MX3005P real time PCR machine, with the subsequent cycling circumstances: preliminary denaturation at $95{ }^{\circ} \mathrm{C}$ for $7 \mathrm{~min}$, then 40 cycles at $95{ }^{\circ} \mathrm{C}$ for 10 seconds and $60{ }^{\circ} \mathrm{C}$ for 30 seconds. Sequences for primers utilized were: AChE (ahead: 5'-GAAGCAGGAATGACGAAGCAG-3') and (backward: 5'GAGGAGGAAAAGGAAGAAGAG-3') ${ }^{23}$, in addition to $\beta$-actin as housekeeping gene (forward: 5'-TCCTCCTGAGCGCAAGTACTCT-3') and (reverse: 5'-GCTCAGTAACAGTCCGCCTAGA3') ${ }^{24}$. The mRNA was standardized to $\beta$-actin mRNA, and comparative gene expression was computed by the stratagene MX3005P software via the relative $\mathrm{CT}$ means $(2-\wedge \wedge \mathrm{CT})^{25}$.

\subsection{Brain hippocampal assessment of malondialdehyde content:}

Malondialdehyde content was measured in accordance with the manufacturer's instructions (Biodiagnostics, Egypt) as mentioned by Ohkawa et al. ${ }^{26}$. Briefly, aliquot from hippocampal tissue homogenates was mixed with thiobarbituric acid to react with malondialdehyde at acidic $\mathrm{pH}$ for $30 \mathrm{~min}$ at temperature of $95^{\circ} \mathrm{C}$, to produce thiobarbituric acid reactive (TBAR) product. The absorbance of the pink product was read at $534 \mathrm{~nm}$.

\subsection{Brain hippocampal assessment of catalase activity:}

Catalase activity was measured in accordance with the manufacturer's instructions (Biodiagnostics, Egypt) as mentioned by Aebi et al. 27. Briefly, catalase in hippocampal tissue homogenate reacted with a known quantity of $\mathrm{H}_{2} \mathrm{O}_{2}$. This was followed by adding catalase inhibitor after exactly one minute to halt the reaction. In the existence of horse radish peroxidase, the residual $\mathrm{H}_{2} \mathrm{O}_{2}$ reacted with 3,5-Dichloro-2-hydroxybenzene sulfonic acid, together with 4-aminophenazone to produce a colored compound, whose color intensity is contrariwise the quantity of catalase in the sample, then absorbances were read at $510 \mathrm{~nm}$.

\subsection{Bone marrow assessment of micronucleus:}

Micronucleus test was carried out on 4 rats per each group ${ }^{28,29}$. Bone marrow was prepared as follows. Both femurs were detached, and all the adhering muscles were dissected out. The bone marrow was removed out from both femurs by flushing with $1 \mathrm{ml}$ fetal calf serum then subsequently centrifuged at $1200 \mathrm{rpm}$ for $15 \mathrm{~min}$. This was followed by supernatant aspiration and cells fixation by cold 3:1 methanol: acetic acid. Afterwards, two smears per animal were set by adding drops of the pellet on slides at angle equals to $45^{\circ}$, then left to dry for 20, then stained by May-Grun Wald and Giemsa stains. Three types of cells were counted under the microscope, nucleated cells $(\mathrm{N})$ these represents the white blood cells, polychromatic erythrocytes (PE) and $\mathrm{PE}$ with micronucleus (MN-PE). The item of recording was the micronucleated $\mathrm{PE}$, not the micronucleus itself; therefore, if a cell had more than one micronucleus, it was recorded as one MN-PE. All slides were examined under light microscope 
(Leica DM2500) at magnification power 100X, using emersion oil for cell counting. Two variables were scored in this analysis:

The cytotoxicity, was expressed as the number of PE to total number of PE and N (\%):

$$
\text { Cytotoxicity } \%=\frac{P E \times 100}{P E+N}
$$

And the genotoxicity, was expressed as the number of MN-PE to total number of PE (\%):

$$
\text { Genotoxicity } \%=\frac{\mathrm{MN}-\mathrm{PE}}{\mathrm{PE}} \times 100
$$

\subsection{Brain hippocampal histopathological examinations:}

The formaldehyde-preserved brain samples were fixed in paraffin wax to be sectioned into $4 \mu \mathrm{m}$ thick sagittal brain sections from the CA3 hippocampal region by means of rotatory microtome. Then the samples were truncated, dehydrated in ethanol, cleared by dipping in Xylene, and then stained by using either Hematoxylin and Eosin (H\&E) or using Nissl staining (Toluidine blue stain) for revelation of intact and degenerated neurons. Nissl stained tissues were examined by summing up of intact neurons by means of microscopic camera (Full HD), managed via Leica application unit for analysis of tissues (Leica Microsystems, Wetzlar, Germany).

\subsection{Analysis of statistics:}

Data were demonstrated as mean \pm S. E.M. Statistical significance was calculated as $\mathrm{P}<0.001$ for AChE gene expression, MDA level, catalase activity and Nissl staining neuronal counting. Concerning the micronucleus test, significance was taken as $\mathrm{P}<0.05$. All statistics was carried out using one-way analysis of variance (ANOVA), then Tukey's multiple comparison test, and were accomplished with GraphPad Prism 5.1 software (GraphPad Software, La Jolla, CA, USA).

\section{RESULTS}

\subsection{Alterations in hippocampal AD biomarker:}

As depicted from figure (2), AD control group resulted in significant increase in AChE gene expression by 5.8 folds when compared to normal group. The effect of PDC injection to AD-rats was much harmful, reaching 7.6 folds when compared with normal rats and 1.3 folds of the AD control. Moreover, PDC single injection resulted in 2.5 folds' elevation when compared to normal rats. Furthermore, when PDC was injected to $\mathrm{AD}$ rats it resulted in 3.04 folds' significant increase than PDC alone.

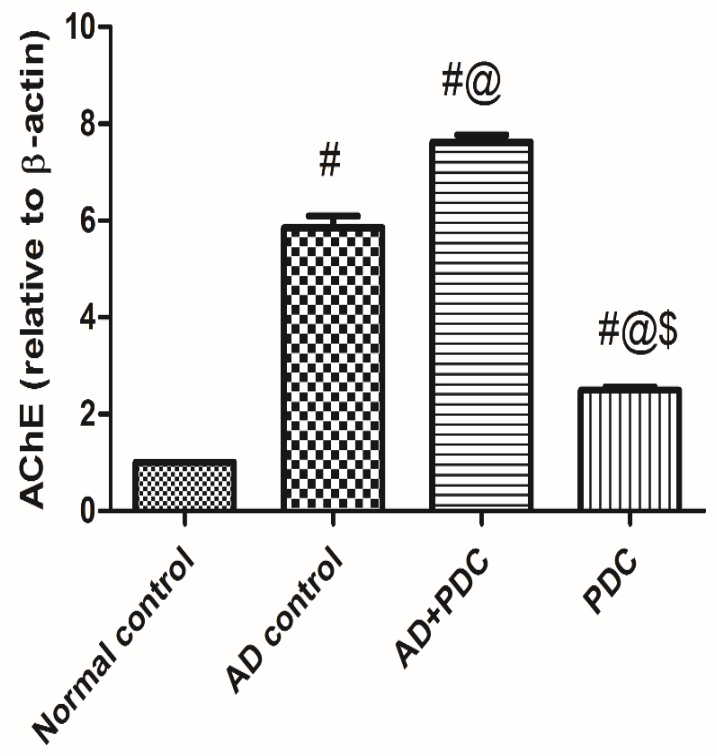

Figure 2: Changes in hippocampal AChE gene expression. Data represent means \pm S.E.M. $(n=6)$. AChE gene expression in brain hippocampal tissues from rats treated with either saline (normal control), LPS (AD control) or LPS+PDC was determined using qRT-PCR. Statistical analysis was carried out using one-way ANOVA followed by Tukey's multiple comparison test. As compared with normal control (\#), AD control (@) and AD injected with PDC (\$), relative to $\beta$-actin. All groups were compared at $\mathrm{p}<0.001$. AChE: acetylcholinesterase, AD: Alzheimer's disease, PDC: potassium dichromate.

\subsection{Alterations in hippocampal oxidative stress} biomarkers:

Here we examined the impact of PDC on oxidative stress indicators (MDA and catalase) produced in brain hippocampi with and without $\mathrm{AD}$. As clear from figure (3A) that LPS resulted in promoting MDA formation by 3.59 folds when compared to normal control. It is also obvious that PDC injection lead to significant increase in MDA formation in hippocampi of AD rats, by 4.63 folds when compared to normal control and 1.29 folds when compared to AD control rats. When compared to PDC alone, the third group showed 1.17-fold significant increase in MDA levels. As presented in figure (3B), injection of LPS lead to increase in catalase activity in rats' hippocampi by 1.23 -folds when compared to normal control. It is also obvious that PDC injection resulted in significant elevation in catalase activity in rats' hippocampi by 2.11 -folds when compared to normal control and 1.71-folds when compared to $\mathrm{AD}$ control rats. Moreover, when 
PDC was injected to AD rats it resulted in 1.2-folds significant increase than PDC alone.
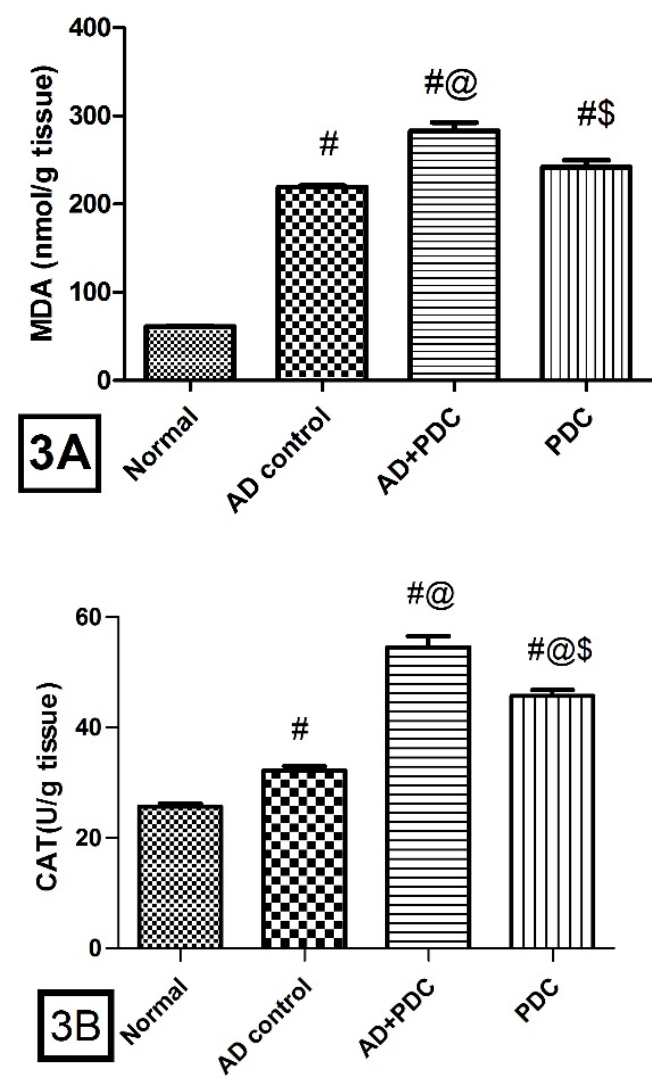

Figure 3. PDC induced oxidative stress in brain hippocampal tissues. (3A) MDA content in brain hippocampal tissues from rats treated with either saline (normal control), LPS (AD control) or LPS+PDC was determined using a TBARS assay kit. Data represent means \pm S.E.M. $(n=6)$. \# Significantly different from normal control group. @ Significantly different from AD control group. \$ Significantly different from AD+PDC group. (3B) CAT activity in brain hippocampal tissues from rats treated with either saline (normal control), LPS (AD control) or LPS+PDC was determined using a $\mathrm{H}_{2} \mathrm{O}_{2}$ assay kit. Data represent means \pm S.E.M. $(n=6)$. As compared with normal control (\#), AD control (@) and AD injected with PDC (\$). All groups were compared at $\mathrm{p}<$ 0.001. MDA: malondialdehyde, CAT: catalase, AD: Alzheimer's disease, PDC: potassium dichromate.

\subsection{Alterations in bone marrow micronuclei and} polychromatic erythrocytes count:

The results of Micronucleus assay (MN) were done on 4 rats per each group, where 2 slides were assayed for each rat (figure 4). As depicted from figure (5A), when talking about polychromatic erythrocytes, it is shown that LPS alone didn't result in significant difference from normal control, but injection of PDC resulted in significant elevation of $\mathrm{PE} \%$ by 1.79 folds when compared to normal, 1.64 folds when compared to $\mathrm{AD}$ rats, and 1.11 folds when compared to PDC alone. On the other hand, when talking about micronuclei (MN-PE\%), a significantly surge was observed when comparing all groups to normal control group, by 3.81 folds in $\mathrm{AD}$ control, 4.63 folds in $\mathrm{AD}+\mathrm{PDC}$, and 4.31 folds in PDC alone. However, no statistically significant variance among other groups when matched together. All these data are represented in table 1 and figure 5.

Table 1.PE, N and MN-PE count / 1000 cells/ slide in rat bone marrow.

\begin{tabular}{|c|c|c|c|}
\hline Group & $\begin{array}{l}\text { PE count / } \\
1000 \text { cells }\end{array}$ & $\begin{array}{l}N \text { count } \\
1000 \text { cells }\end{array}$ & $\begin{array}{l}\text { MN-PE } \\
\text { count } \\
\text { total PE }\end{array}$ \\
\hline $\begin{array}{l}\text { Normal } \\
\text { control }\end{array}$ & $199 \pm 10$ & $801 \pm 10$ & $2.4 \pm 0.32$ \\
\hline $\begin{array}{l}A D \\
\text { control }\end{array}$ & $\begin{array}{c}218.94 \\
\pm 9.4\end{array}$ & $782 \pm 9.4$ & $7.6 \pm 0.53^{\#}$ \\
\hline $\begin{array}{l}A D+P \\
D C\end{array}$ & $\begin{array}{c}357 \pm 5.2^{\# @} \\
\$\end{array}$ & $\begin{array}{c}643 \pm 5.2^{\# @} \\
s\end{array}$ & $15 \pm 1.2^{\# @}$ \\
\hline$P D C$ & $\begin{array}{c}321.8 \pm 7.8 \\
4^{\# @}\end{array}$ & $\begin{array}{c}678.3 \pm 7.8 \\
4^{\# @}\end{array}$ & $\begin{array}{c}12.88 \pm 0.7 \\
4^{\# @}\end{array}$ \\
\hline
\end{tabular}

Data represent means \pm S.E.M. $(\mathrm{n}=8)$. \# Significantly different from normal control group at $\mathrm{p}<0.05$ @ Significantly different from $\mathrm{AD}$ control group at $\mathrm{p}<0.05$. $\$$ Significantly different from PDC alone. PE: Polychromatic erythrocytes; MN-PE: Micronucleated polychromatic erythrocytes; AD: Alzheimer's disease; PDC: potassium dichromate.

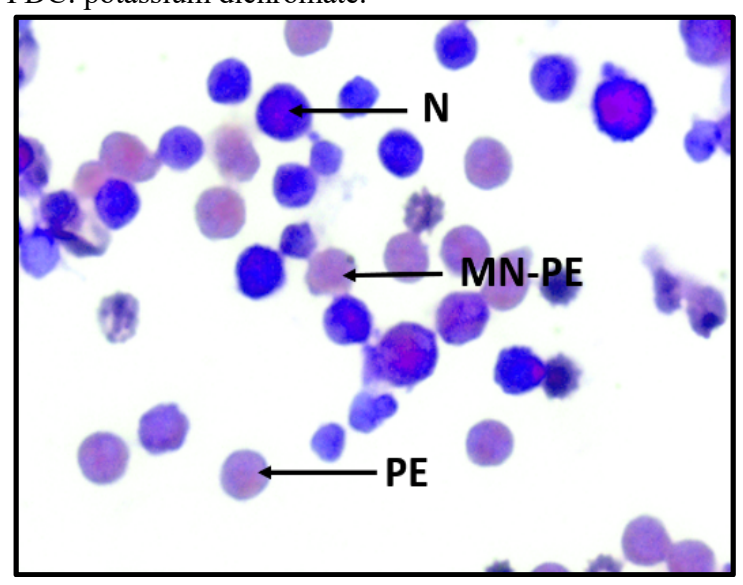

Figure 4. Bone marrow cells: nucleated cells (N), polychromatic erythrocytes (PE), and micronucleatedpolychromatic erythrocytes (MN-PE).

\subsection{Alterations in features of CA3 hippocampal} tissue and its number of surviving neurons:

An additional expression of the aforementioned biochemical and cytogenetic outcomes, figure 6 illustrates the changes in the photomicrographs of the $H \& E$ stained sections of the various injections (from B to D) when related to normal tissue sections (A) of the intact $\mathrm{CA} 3$ region of brain hippocampi. These results were summarized in figure 7 (A to D), where staining with the Nissl stain showed the differences in surviving neurons throughout the different groups. The AD+PDC revealed minimal count of surviving neurons. These results are also presented graphically in figure (8). 

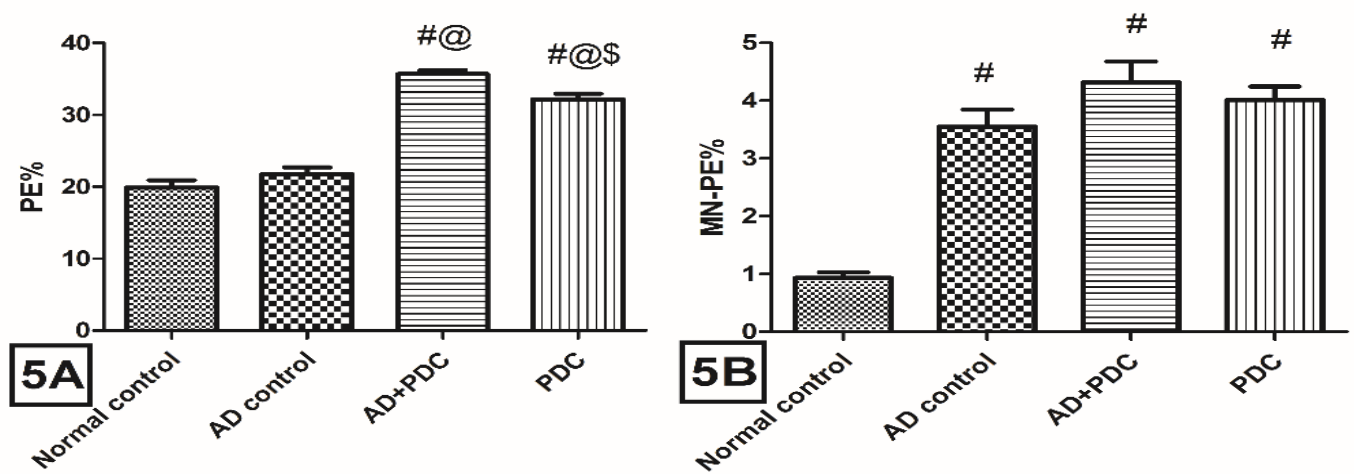

Figure 5. $\mathrm{PE} \%$ \& $\mathrm{MN}-\mathrm{PE} \%$ in rat bone marrow. (5A): $\mathrm{PE} \%$, (5B) $\mathrm{MN}-\mathrm{PE} \%$ in bone marrow from rats treated with either saline (normal control), LPS (AD control) or LPS+PDC was determined using Micronucleus assay method microscopically. Data represent means \pm S.E.M. (n=8 slides/group). As compared with normal control (\#), AD control (@) and AD injected with PDC (\$). All groups were compared at $\mathrm{p}<0.05$. PE: polychromatic erythrocytes, MN-PE: micronucleated polychromatic erythrocytes, AD: Alzheimer's disease, PDC: potassium dichromate.
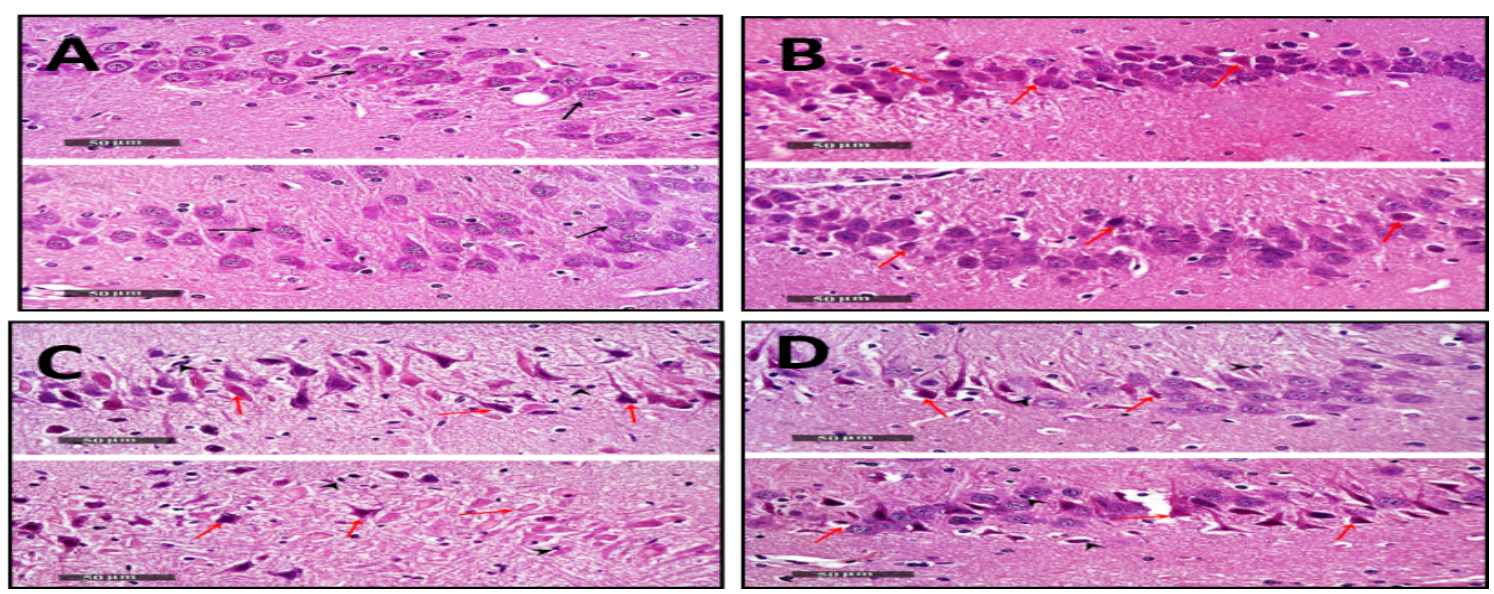

Figure 6. Alterations in histopathological photomicrographs of CA3 hippocampal region. Normal Control (A) samples demonstrated normal histological structures of hippocampal layers with apparent intact polymorphic and pyramidal neurons with intact nuclear and subcellular details (black arrow). Intact intercellular matrix was observed with normal glial cells infiltrates. Alzheimer's disease control (B) samples showed moderate records of necrotic and degenerated pyramidal neurons (red arrow) alternated with apparent intact neurons with moderate perineuronal and intercellular edema of brain matrix. Alzheimer's disease intoxicated with potassium dichromate by single i.p. injection (C) samples revealed abundant sever records of degenerative and necrotic pyramidal neurons (red arrow) alternated with few apparent intact cells, and accompanied with severe intercellular edema and vacuolization of brain matrix with mild records of reactive glial cells infiltrates (arrow head). Potassium dichromate single injection (D) samples showed milder records of degenerated and necrotic neurons in comparison with Alzheimer's disease intoxicated with potassium dichromate samples, with higher records of apparent intact neurons. (H\&E; $50 \mu \mathrm{m}$ ).
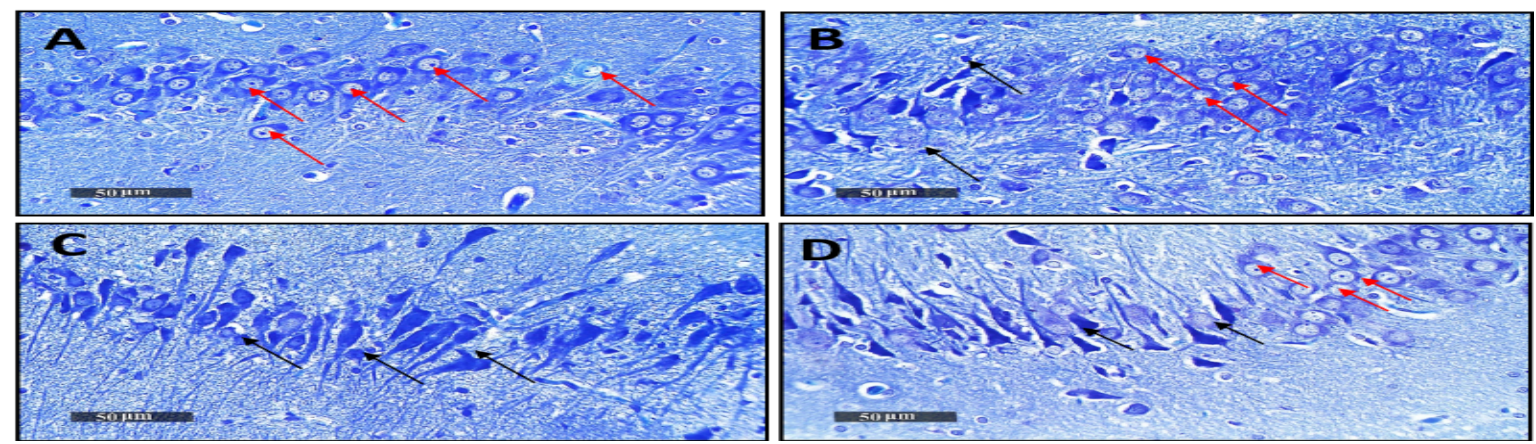

Figure 7. Effect of different groups on neuronal survival count. The Nissl stain reveal a decrease in the number of viable neurons in (B) Alzheimer's disease control, (C) Alzheimer's disease injected with potassium dichromate, and (D) injected with potassium dichromate only, compared to the (A) normal control group. (Nissl stain; $50 \mu \mathrm{m}$ ). Red arrow: intact neurons, black arrow: damaged neurons. 


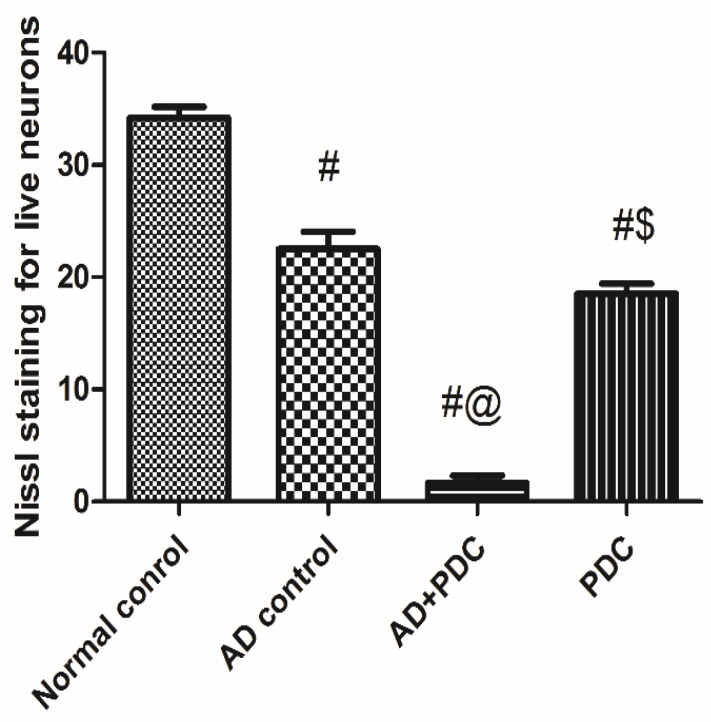

Figure 9. Show the living neurons count. Data are introduced as mean \pm S.E M (n=4). Statistical analysis was done by one-way ANOVA then Tukey's multiple comparison test. When compared with normal control (\#), AD control (@), and AD+PDC $(\$)$ groups at $\mathrm{P}<0.001$. AD: Alzheimer's disease, PDC: potassium dichromate.

\section{DISCUSSION}

This research aimed to highlight the possible potential brain injury and cytogenotoxicity among individuals suffering from Alzheimer's disease (AD), after the exposure to $\mathrm{Cr}^{6+}$ dust environmentally or occupationally, in the form of potassium dichromate (PDC) compound. The hippocampus is a brain region, that consists of 3 fields, namely CA1, CA2, and CA3 in addition to the subiculum. A transfer of information occurs from dentate gyrus to CA3 then incorporated in CA1 ${ }^{30}$. Lately, the CA3 brain hippocampal region has attracted foremost consideration for its explicit role in memory practices, vulnerability to seizures and neurodegenerative processes. ${ }^{31}$.

The previous reports stated the association between Alzheimer's Disease and the significant diminish in brain hippocampal and cortical acetylcholine (ACh) content, as a result of elevated acetylcholinesterase (AChE) synthesis and activity 10. That's why we used AChE gene expression in brain hippocampus as a marker of $\mathrm{AD}$ induction. The present study annotated the histopathological alterations that may occur within $\mathrm{CA} 3$ region in the brain hippocampus, as a result of injection of PDC.

The brain, with its great oxygen-consuming and lipid-generous levels, greatly permits oxidative stress. Therefore, oxidative stress-induced damage to the brain has a robust possibility to negatively influence the CNS purposes ${ }^{32}$. Lipid peroxidation is the most noticeable feature in which degenerative change is most pronounced in the $\mathrm{AD}$ brain ${ }^{33}$.
Catalase breakdown the toxic metabolic by-product hydrogen peroxide, into water and oxygen ${ }^{34}$. As aforementioned in earlier studies, catalase is a major detoxifying enzyme found in the peroxisomes of the brain ${ }^{33}$. Unfortunately, the brain possesses 50 times less catalase when compared to hepatocytes ${ }^{35}$, so it is far more prune to oxidative stress.

For the last 4 decades, the in vivo micronucleus assay (MN) has turned out to be one of the most reliable methods to evaluate the cytotoxicity and genotoxicity of numerous physical and chemical elements ${ }^{20}$. It was confirmed by many studies that an elevation in the micronuclei frequency is associated with several neurodegenerative diseases ${ }^{36}$. The MN test has some advantages over other DNA damage detection techniques: (i) faster; (ii) cheaper; (iii) simpler than chromosomal aberration assessment. Although the $\mathrm{MN}$ assay cannot give information about chromosomal damage type, it is informative when the exposure causes aneugenic effects. By engaging all these features, this methodology becomes highly applicable in routine mutagenesis studies ${ }^{37}$.

Lipopolysaccharide (LPS) is a crucial element in Gram-negative bacteria cell wall and has the ability to result in sepses, shocks and microcirculation disturbances ${ }^{38}$. Our results showed significant rise in $\mathrm{AChE}$ gene expression in groups injected with LPS. This is compatible with the results of Ming et al. ${ }^{39}$ and Tyagi et al. ${ }^{40}$. In addition, the results showed upsurged malondialdehyde (MDA) indicating elevated oxidative stress in the brain hippocampus of LPS-injected rats. This is compatible with the results of Mokhtari-Zaer et al. ${ }^{41}$ and Bargi et al. ${ }^{42}$. Furthermore, the catalase activity is boosted in LPS-rats a result of an adaptive response to the oxidative stress ${ }^{34}$. Illee et al. ${ }^{43}$ showed that LPS-single injection increased the MN instance, and that was the same as our results with LPS-injection for one week. In our study, LPS didn't exert any cytotoxic significance from normal control, as demonstrated by PE\%. This concludes that LPS has genotoxic but not cytotoxic effect. But this is in contrast with the findings of Sharifi et al. ${ }^{44}$, who stated that LPS enhanced expression of apoptotic proteins compared to controls.

Potassium dichromate $\left(\mathrm{K}_{2} \mathrm{Cr}_{2} \mathrm{O}_{7}\right)$ is a toxic and hydrophilic heavy metal, that is mobile in the natural environment ${ }^{45}$. It is one of the most severe chromium compounds. It increases neurobehavioral disturbances in humans and experimental animals ${ }^{46}$. In our present study, the rats were intraperitoneally intoxicated with PDC for once after induction of AD. This injection elevated the AChE gene expression in the hippocampus of $\mathrm{AD}$ rats, proving its ability to pass blood brain barrier, as mentioned by Salama et. al. 5. Our results showed that a single PDC administration induced brain oxidative stress in rats as evidenced by the increase in MDA content when 
compared to normal rats and $\mathrm{AD}$ rats, as shown by Salama et. al ${ }^{5}$. Moreover, the observed increment in catalase activity level in groups injected with PDC may be justified that it is a defense mechanism against chromium-induced oxidative stress by enhancing the antioxidant enzyme activity. Since $\mathrm{MN}$ arises from DNA-breaks, Cr (VI) itself is nonreactive with DNA, though, during its reduction, the produced metabolites radicals can afterwards attack macromolecules, ending with multiform DNA damages, as strand breakage ${ }^{34}$. Single injection of PDC significantly elevated the PE\% when compared to normal and AD rats. This indicates its cytotoxic effect. In addition, PDC injection elevated $\mathrm{MN} \%$ higher than normal, but no significant increase more than $\mathrm{AD}$ rats. These findings showed that PDC exerted the same genotoxicity as LPS.

\section{CONCLUSIONS}

This study showed that PDC exposure would be an extreme harm to $\mathrm{AD}$ rats, decreasing their ACh, increasing their brain oxidative stress, and cytogenotoxic levels by increasing the MN\% and $\mathrm{PE} \%$. These results confirm its ability to deteriorate the AD case.

Funding statement: This research received no external funding.

Conflicts of Interest: The authors declare no conflicts of interest.

Ethical Statement: The protocol followed in this study was approved by Al-Azhar Faculty of Pharmacy (Girls) scientific research ethical committee (no. 97, 2016).

Author contribution: This work was carried out in collaboration between all authors. Iman Hassan Ibrahim and Ezzat Ibrahim Aboul-Ela designed the study. Marwa Ashraf Essa performed the experiments and wrote the manuscript. Iman Hassan Ibrahim, Ezzat Ibrahim Aboul-Ela and Marwa Ashraf Essa analyzed the data and revised the manuscript.

List of abbreviations: PDC: Potassium dichromate; AD: Alzheimer's disease; LPS: Lipopolysaccharide: AChE: Acetylcholinesterase; ACh: Acetylcholine; MDA: Malondialdehyde; CAT: Catalase; MN: Micronucleus; MN-PE: Micronucleated polychromatic erythrocytes; PE: Polychromatic erythrocytes; N: Nucleated cells; A $\beta$ : Amyloid $\beta$.

Authors consent for publication: We, the authors, give our consent for the publication of this research paper to be published in Azhar International Journal of Pharmaceutical And Medical Sciences

\section{REFERENCES}

1. Khan M, Parvez S. Hesperidin ameliorates heavy metal induced toxicity mediated by oxidative stress in brain of Wistar rats. J Trace Elem Med Bio. 2015 Jul 1; 31:53-60. DOI: https://doi.org/10.1016/j.jtemb.2015.03.002

2. Maccotta A, Cosentino C, Coccioni R, Frontalini F, Scopelliti G, Caruso A. Distribution of $\mathrm{Cr}$ and $\mathrm{Pb}$ in artificial sea water and their sorption in marine sediments: an example from experimental mesocosms. Environ Sci Pollut Res. 2016 Dec 1;23(23):24068-80. DOI: 10.1007/s11356-0167630-0

3. Mitra S, Sarkar A, Sen S. Removal of chromium from industrial effluents using nanotechnology: a review. Nanotechnol Environ Eng. 2017 Dec 1;2(1):1-4. DOI: https://doi.org/10.1007/s41204017-0022-y

4. Eman S, Farag A. Chromium-induced hepatotoxicity and potential protective effect of selenium in adult male albino rat: a histological, immuno-histochemical and molecular study. Medical J Cairo Univ. 2020 Mar 1;88(March):18796. DOI: 10.21608/MJCU.2020.93977

5. Salama A, Hegazy R, Hassan A. Intranasal chromium induces acute brain and lung injuries in rats: Assessment of different potential hazardous effects of environmental and occupational exposure to chromium and introduction of a novel pharmacological and toxicological animal model. PloS One. 2016 Dec 20;11(12):e0168688. DOI: 10.1371/journal.pone.0168688

6. Alzheimer's Association. (2021) Alzheimer's Disease Facts and Figures. Alzheimers Dement 2021;17(3). URL: https:/www.alz.org/alzheimersdementia/facts-figures

7. Pippin J, Cavanaugh S, Pistollato F. Animal research for Alzheimer disease: failures of science and ethics. In Animal Experimentation: Working Towards a Paradigm Change Book, Publisher: Brill. Volume 222019 Apr 30; 480-516. DOI: https://doi.org/10.1163/9789004391192_021

8. Yamada K, Nabeshima T. Animal models of Alzheimer's disease and evaluation of anti-dementia drugs. Pharmacol \& Therap. 2000 Nov 1;88(2):93113. DOI: $10.1016 / \mathrm{s} 0163-7258(00) 00081-4$ 
9. Wang H, Xu Z, Feng C, Wang Y, Jia X, Wu A, et al. Changes of learning and memory in aged rats after isoflurane inhalational anaesthesia correlated with hippocampal acetylcholine level. In Annal Franc D'anesth Reanim Publisher: Elsevier Masson. 2012 Mar 1 (Vol. 31, No. 3, pp. e61-e66). DOI: 10.1016/j.annfar.2011.02.005

10. García-Ayllón M, Small D, Avila J, Sáez-Valero J. Revisiting the role of acetylcholinesterase in Alzheimer's disease: cross-talk with P-tau and $\beta$ amyloid. Front Molec Neurosci. 2011 Sep 13;4:22. DOI: https://doi.org/10.3389/fnmol.2011.00022

11. Lee J, Lee Y, Yuk D, Choi D, Ban S, Oh K, et al. Neuro-inflammation induced by lipopolysaccharide causes cognitive impairment through enhancement of beta-amyloid generation. J Neuroinflam. 2008 Dec;5(1):1-4. DOI: 10.1186/1742-2094-5-37

12. Giovannini M, Scali C, Prosperi C, Bellucci A, Vannucchi M, Rosi S, et al. $\beta$-Amyloid-induced inflammation and cholinergic hypofunction in the rat brain in vivo: involvement of the p38MAPK pathway. Neurobiol Dis. 2002 Nov 1;11(2):257-74. DOI: $10.1006 /$ nbdi.2002.0538

13. Singh R, Thota S, Bansal R. Studies on 16, 17pyrazoline substituted heterosteroids as antiAlzheimer and anti-Parkinsonian agents using LPS induced neuroinflammation models of mice and rats. ACS Chem Neurosci. 2018 Feb 21;9(2):272-83. DOI:

https://doi.org/10.1021/acschemneuro.7b00303

14. Weller J, Budson A. Current understanding of Alzheimer's disease diagnosis and treatment. F1000Research. 2018;7. DOI: https://doi.org/10.12688/f1000research.14506.1

15. Maynard C, Bush A, Masters C, Cappai R, Li Q. Metals and amyloid- $\beta$ in Alzheimer's disease. Int. J. Clin. Exp. Pathol. 2005 Jun;86(3):147-59. DOI: 10.1111/j.0959-9673.2005.00434.x

16. Iqbal G, Ahmed T. Co-exposure of metals and high fat diet causes aging like neuropathological changes in non-aged mice brain. Brain Res Bull. 2019 Apr 1;147:148-58. DOI: https://doi.org/10.1016/j.brainresbull.2019.02.013

17. Hayashi M. The micronucleus test-most widely used in vivo genotoxicity test. Genes Environ. 2016 Dec;38(1):1-6. DOI: https://doi.org/10.1186/s41021016-0044-X

18. Heddle J. Chapter 1: A Short Personal History of Micronuclei, in The Micronucleus Assay in
Toxicology, Publisher: Royal Society Of Chemistry 2019, pp. 1-7 DOI: 10.1039/9781788013604-00001

19. Schmid W. The micronucleus test. Mutat Res. 1975 Feb;31(1):9-15. DOI: 10.1016/01651161(75)90058-8

20. Sommer S, Buraczewska I, Kruszewski M. Micronucleus assay: The state of art, and future directions. Int J Mol Sci. 2020 Jan;21(4):1534. DOI: https://doi.org/10.3390/ijms21041534

21. Zhu B, Wang Z, Ding J, Liu N, Wang D, Ding L, et al. Chronic lipopolysaccharide exposure induces cognitive dysfunction without affecting BDNF expression in the rat hippocampus. Exp Therap Med. 2014 Mar 1;7(3):750-4. DOI: https://doi.org/10.3892/etm.2014.1479

22. Hassan M, Abd-Elwahab W, Megahed R, Mohammed A. An Evaluation of Hepatotoxicity, Nephrotoxicity, and Genotoxicity Induced by Acute Toxicity of Hexavalent Chromium and Comparison of the Possible Protective Role of Selenium and Vitamin E on These Effects. Ain-Shams J Foren Med Clin Toxicol, 2019; 33(2): 48-58. DOI: 10.21608/AJFM.2019.36574

23. Kazi AI, Oommen A. The effect of acute severe monocrotophos poisoning on inhibition, expression and activity of acetylcholinesterase in different rat brain regions. Neurotox. 2012 Oct 1;33(5):1284-90. DOI: https://doi.org/10.1016/j.neuro.2012.07.010

24. Banni M, Messaoudi I, Said L, El Heni J, Kerkeni A, Said K. Metallothionein gene expression in liver of rats exposed to cadmium and supplemented with zinc and selenium. Arch Environ Contam Toxicol. 2010 Oct;59(3):513-9. DOI: https://doi.org/10.1007/s00244-010-9494-5

25. Schmittgen T, Livak K. Analyzing real-time PCR data by the comparative $\mathrm{C} \mathrm{T}$ method. Nat Protoc. 2008 Jun;3(6):1101. DOI: 10.1038/nprot.2008.73

26. Ohkawa H, Ohishi N, Yagi K. Assay for lipid peroxides in animal tissues by thiobarbituric acid reaction. Analyt Biochem. 1979 Jun 1;95(2):351-8. DOI: 10.1016/0003-2697(79)90738-3

27. Aebi H. Catalase in vitro. Method Enzymol. 1984 Jan 1;105:121-6. DOI: 10.1016/s00766879(84)05016-3

28. Salah H, Aboul-Ela E, Swelim H. Ameliorative Effect of Peach Seed Extract on CyclophosphamideInduced Cytogenetic and Histological Effects in Mice. Intl J Gen Genom. 2019 Dec 5;7(4):136. DOI: $10.11648 / j . i j g g .20190704 .19$ 
29. Custer L, Doherty A, Bemis J, Proudlock R. The In Vivo Rodent Micronucleus Assay. Gen Toxicol Test 2016 Jan 1 (pp. 269-322). Academic Press. DOI: https://doi.org/10.1016/B978-0-12-800764-8.000082

30. Ramezani M, Darbandi N, Khodagholi F, Hashemi A. Myricetin protects hippocampal CA3 pyramidal neurons and improves learning and memory impairments in rats with Alzheimer's disease. Neur Regen Res. 2016 Dec;11(12):1976. DOI: $10.4103 / 1673-5374.197141$

31. Cherubini E, Miles RM. The CA3 region of the hippocampus: how is it? What is it for? How does it do it?. Front Cell Neurosci. 2015 Feb 5;9:19. DOI: https://doi.org/10.3389/fncel.2015.00019

32. Salim S. Oxidative stress and the central nervous system. J Pharmacol Exp Therap. 2017 Jan 1;360(1):201-5. DOI: 10.1124/jpet.116.237503

33. Huang W, Zhang X, Chen W. Role of oxidative stress in Alzheimer's disease. Biomed Reports. 2016 May 1;4(5):519-22. DOI: 10.3892/br.2016.630

34. Patlolla A, Barnes C, Yedjou C, Velma V, Tchounwou P. Oxidative stress, DNA damage, and antioxidant enzyme activity induced by hexavalent chromium in Sprague-Dawley rats. Environ Toxicol. 2009 Feb;24(1):66-73. DOI: 10.1002/tox.20395

35. Cobley J, Fiorello M, Bailey D. 13 Reasons why the brain is susceptible to oxidative stress. Redox Biol. 2018 May 1;15:490-503. DOI: https://doi.org/10.1016/j.redox.2018.01.008

36. Rivers E, McIntyre L, Morro D, Rivers K. Early and innovative interventions for severe sepsis and septic shock: taking advantage of a window of opportunity. CMAJ. 2005 Oct 25;173(9):1054-65. DOI: $10.1503 / \mathrm{cmaj} .050632$

37. Da Rocha C, Dos Santos R, Bahia M, Da Cunha L, Ribeiro H, Burbano R. The micronucleus assay in fish species as an important tool for xenobiotic exposure risk assessment-a brief review and an example using neotropical fish exposed to methylmercury. Rev Fish Sci. 2009 Oct 2;17(4):47884.

DOI:

https://doi.org/10.1080/10641260903067852

38. Solov'eva T, Davydova V, Krasikova I, Yermak I. Marine compounds with therapeutic potential in gram-negative sepsis. Marine Drugs. 2013 Jun;11(6):2216-29. DOI: 10.3390/md11062216
39. Ming Z, Wotton C, Appleton R, Ching J, Loewen M, Sawicki G, et al. Systemic lipopolysaccharidemediated alteration of cortical neuromodulation involves increases in monoamine oxidase- $\mathrm{A}$ and acetylcholinesterase activity. J Neuroinflam. 2015 Dec;12(1):1-1. DOI: https://doi.org/10.1186/s12974015-0259-y

40. Tyagi E, Agrawal R, Nath C, Shukla R. Influence of LPS-induced neuroinflammation on acetylcholinesterase activity in rat brain. $\mathrm{J}$ Neuroimmunol. 2008 Dec 15;205(1-2):51-6. DOI: 10.1016/j.jneuroim.2008.08.015

41. Mokhtari-Zaer A, Hosseini M, Salmani H, Arab Z, Zareian P. Vitamin D3 attenuates lipopolysaccharide-induced cognitive impairment in rats by inhibiting inflammation and oxidative stress. Life Sci. 2020 Jul 15;253:117703. DOI: 10.1016/j.1fs.2020.117703

42. Bargi R, Asgharzadeh F, Beheshti F, Hosseini M, Sadeghnia H, Khazaei M. The effects of thymoquinone on hippocampal cytokine level, brain oxidative stress status and memory deficits induced by lipopolysaccharide in rats. Cytokine. 2017 Aug 1;96:173-84.

DOI:

https://doi.org/10.1016/j.cyto.2017.04.015

43. İlce Z, Bekdemir FO, Pandır D. Acute toxic effect of lipopolysaccharides to blood tissue in rats and responses to vitamin $\mathrm{E}$ and sodium selenite. J Food Biochem. 2019 Dec;43(12):e13060. DOI: 10.1111/jfbc. 13060

44. Sharifi A, Hoda F, Noor A. Studying the effect of LPS on cytotoxicity and apoptosis in PC12 neuronal cells: role of $\mathrm{Bax}, \mathrm{Bcl}-2$, and Caspase- 3 protein expression. Toxicol Mechan Meth. 2010 Jul 1;20(6):316-20. DOI: $10.3109 / 15376516.2010 .486420$

45. Gode F, Pehlivan E. Removal of Cr (VI) from aqueous solution by two Lewatit-anion exchange resins. J Hazard Mater. 2005 Mar 17;119(1-3):17582. DOI: 10.1016/j.jhazmat.2004.12.004

46. Soudani N, Troudi A, Amara IB, Bouaziz H, Boudawara T, Zeghal N. Ameliorating effect of selenium on chromium (VI)-induced oxidative damage in the brain of adult rats. J Physiol Biochem. 2012 Sep 1;68(3):397-409. DOI: 10.1007/s13105012-0152-4 